\title{
Evaluation of the Antitumor Activity by Ni Nanoparticles with Verbascoside
}

\author{
Mingyue Chen, ${ }^{1}$ Yaqin Zhang, ${ }^{2}$ Bin Huang, ${ }^{3}$ Xueming Yang, ${ }^{4}$ Yunong Wu, ${ }^{4}$ Bin Liu, \\ Yi Yuan, ${ }^{4}$ and Gen Zhang ${ }^{6}$ \\ ${ }^{1}$ Department of Biomedical Engineering, School of Kangda, Nanjing Medical University, Nanjing 210029, China \\ ${ }^{2}$ Department of Biochemical Molecular, School of Basic Medical Sciences, Nanjing Medical University, Nanjing 210029, China \\ ${ }^{3}$ Department of Radiology, Nanjing Brain Hospital, Nanjing Medical University, Nanjing 210009, China \\ ${ }^{4}$ Institute of Stomatology, Nanjing Medical University, Nanjing 210029, China \\ ${ }^{5}$ Department of Biomedical Engineering, School of Basic Medical Sciences, Nanjing Medical University, Nanjing 210029, China \\ ${ }^{6}$ Department of Cell Biology, School of Basic Medical Sciences, Nanjing Medical University, Nanjing 210029, China
}

Correspondence should be addressed to Yi Yuan; xpyywy@126.com and Gen Zhang; zhanggen123@126.com

Received 1 September 2013; Revised 25 October 2013; Accepted 4 November 2013

Academic Editor: Mengnan Qu

Copyright (C) 2013 Mingyue Chen et al. This is an open access article distributed under the Creative Commons Attribution License, which permits unrestricted use, distribution, and reproduction in any medium, provided the original work is properly cited.

\begin{abstract}
Verbascoside (VB) has attracted a great deal of attention due to ITS pharmacological properties. In our study, we synthesized a multifunctional verbascoside coated Ni nanoparticles (VB-Ni). Transmission electron microscopy (TEM) and high performance liquid chromatography (HPLC) display the characteristics of VB-Ni nanoparticles. Compared with VB, VB-Ni has been proven to induce apoptosis and resist the growth of doxorubicin-resistant K562 cells in vitro and in vivo. Thus, VB-Ni nanoparticles can be thought of as an ideal mode of cancer treatment.
\end{abstract}

\section{Introduction}

Cancer is quickly becoming the leading cause of death worldwide [1]. Nickel nanoparticles (Ni NPs) have been applied in a wide range of fields due to their unique structure and properties [2-6]. Over the past decades, nanoparticles have been increasingly applied in clinical diagnoses and cancer therapy with promising and far-ranging prospects in the medical fields. Increasing interest in the application of nanotechnology for cancer therapy has been noted [7-10]. Previous phytochemical studies have demonstrated that flavonoids and phenylpropanoid glycosides are major bioactive constituents of the Tsoong herb (Chinese name: Banchunmaxianhao, BCM) [11]. Among these constituents, VB has attracted a great deal of attention due to its pharmacological properties [12-17]. Its properties include hepatoprotective, anti-inflammatory, antitumor, cytotoxic, and antioxidant activities [18-20].

In recent years, many studies on the therapeutic effect of drug-loaded nanoparticles have become a hot spot
[21, 22]. Based on the above considerations, we have verified the biological effects of VB-Ni nanoparticles on treating cancer cells $[23,24]$. These observations indicate their great potential in clinical and biomedical applications.

\section{Materials and Methods}

2.1. Materials. BCM were collected from Gangcha, QingHai, China, and identified by Professor Li-Juan Mei (Northwest Institute of Plateau Biology, Chinese Academy of Sciences). Materials used for HPLC analysis were of analytical grade.

2.2. Cell Culture. K562 cells were purchased from Tianjin Institute of Hematology and cultured in Dulbecco's Modification of Eagle's Medium (DMEM) supplemented with $10 \%$ FBS (GIBCO) and penicillin $(100 \mathrm{U} / \mathrm{mL}) /$ streptomycin $(100 \mathrm{mg} / \mathrm{mL})$ at $37^{\circ} \mathrm{C}$ in a $5 \% \mathrm{CO}_{2}$, water-saturated atmosphere. To test the function of $\mathrm{VB}-\mathrm{Ni}, \mathrm{VB}-\mathrm{Ni}$, or $\mathrm{VB}$ was added to K562 cells in the same concentration. Cells were 
observed by microscope after 48 or $72 \mathrm{~h}$ treatment, using DNA Ladder to detect the apoptosis of cells.

2.3. Extract VB from BCM Plant. BCM (500 g) were powdered and extracted three times with $70 \% \mathrm{EtOH}$ under reflux. After concentration under vacuum, the residues were suspended in distilled water and extracted with light petroleum, EtOAc, and n-butanol, respectively. The n-butanol solutions were evaporated to dryness under vacuum at $70^{\circ} \mathrm{C}$ to generate n-butanol extract, which was loaded on silica gel column and eluted with various proportions of a mixture of chloroform : methanol. The chloroform : methanol $(3: 1)$ fraction was concentrated to produce crude sample for subsequent high-speed counter-current chromatography (HSCCC) isolation and purification. With a two-phase solvent system composed of chloroform: n-butanol: methanol: water $(4: 3: 4: 5, \mathrm{v} / \mathrm{v})$, the crude sample was separated to yield VB.

2.4. Preparation of Drug-Loaded Ni Nanoparticle. We mixed $2 \mathrm{mg} \mathrm{VB}$ and $30 \mathrm{mg}$ Ni nanoparticles with $\mathrm{ddH}_{2} \mathrm{O}$ in nitrogen environment. Then, we separated the final product from the mixture solution by magnet, washed them for three times, and added $300 \mathrm{~mL}$ distilled water to suspend. Finally, VB$\mathrm{Ni}$ nanoparticles were measured by transmission electron microscope (TEM).

2.5. DNA Fragmentation Assay. K562 cells were incubated with $\mathrm{VB}, \mathrm{Ni}$, or $\mathrm{VB}-\mathrm{Ni}$ for $24 \mathrm{~h}, 48 \mathrm{~h}$, and $72 \mathrm{~h}$, respectively. The untreated cells served as controls. DNA was extracted from K562 cells using Apoptotic DNA ladder isolation kit (Yuan Ping Hao Biotechnology Co., Ltd, Beijing, China), and then loaded onto $1 \%$ agarose gel. The DNA ladders stained with ethidium bromide were visualized under UV light.

2.6. Acridine Orange/Ethidium Bromide (AO/EB) Staining to Detect Apoptosis. K562 cells were incubated with VB$\mathrm{Ni}$ for $48 \mathrm{~h}$ or $72 \mathrm{~h}$. To stain apoptotic cells, the cells were trypsinized for $5 \mathrm{~min}$ before adding $1 \mu \mathrm{L}$ of $\mathrm{AO} / \mathrm{EB}$ dye mixture $(100 \mu \mathrm{g} / \mathrm{mL}$ acridine orange and $100 \mu \mathrm{g} / \mathrm{mL}$ ethidium bromide) to each well. Then, cells were viewed under the fluorescent light microscope.

2.7. Experimental Animals. The female mice (6-week old) were purchased from the Animal Feeding Farm of National Institute for the Control of Pharmaceutical and Biological Products (China). All K562 tumor C57 mice were housed in the animal facility, and animal experiments, (1) control $(n=3),(2) \mathrm{VB}(n=5),(3) \mathrm{VB}-\mathrm{Ni}$ plus a magnet fixed under skin close to the tumor site $(n=5)$, that were conducted followed the guidelines by the Animal Research Ethics Board of Nanjing Medical University. Animals were kept in the facility with free access to food and water. Injection was intravenously administered by tail vein at days $0,2,4,6,8,10$, $12,14,16$, and 18 . The tumor volume of mice was measured and calculated at the 20th day after treatment. The tumor volume

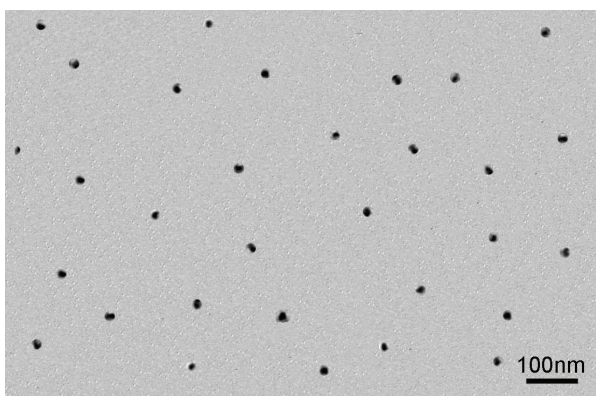

FIGURE 1: TEM images of VB-Ni nanoparticle. TEM image of an individual nanocrystal of $\mathrm{VB}-\mathrm{Ni}$.

calculation was performed using the formula $(\pi \times$ long axis $\times$ short axis $\times$ short axis) $/ 6$.

\section{Results}

3.1. Synthesis and Characterization of VB-Ni Nanoparticles. In our previous study, the structure of VB has been identified and synthesized through HPLC analysis. And the NMR data of VB was in agreement with published data [25]. Herein, we further measured the size of VB-Ni nanoparticle, which was synthesized successfully by mixed $2 \mathrm{mg}$ VB with $30 \mathrm{mg} \mathrm{Ni}$ in solution. As shown in Figure 1, the average diameter of VB$\mathrm{Ni}$ nanoparticle was about $10 \mathrm{~nm}$ in TEM image. The size of VB-Ni nanoparticles was about $15 \mathrm{~nm}$ in cell culture medium through particle sizer analysis, which was relatively uniform and stable (unpublished data).

3.2. The Effects of $\mathrm{VB}-\mathrm{Ni}$ in Recipient $\mathrm{K} 562$ Cells. Many researchers including us have reported that $\mathrm{VB}$ components can increase the apoptosis and inhibit the growth of cancer cells in vitro and in vivo [26]. As a new nanoparticle, we also determined the effect of VB-Ni in doxorubicin-resistant K562 cells. Firstly, K562 cells were incubated for 24 hours with the same concentration of VB and VB-Ni. We found that the apoptosis level was higher in VB-Ni group than VB group (Figures 2(A), 2(b), and (c)). However, to study the relationship between time and the enhanced effect of apoptosis in K562 cells, we treated the cells with VB-Ni at different time points. We further detected the apoptosis level of K562 cells after treatment of VB-Ni. The result demonstrated that the apoptosis rate of K562 cells was further enhanced after $72 \mathrm{~h}$ treatment than $24 \mathrm{~h}$ (Figures $2(\mathrm{~A})$ and (d)). Consistent with our hypothesis, VB-Ni was effective to increase the apoptosis of cancer cells. Besides, we observed a similar inhibitory effect of VB-Ni on viability or survival in K562 cells through MTT assay (Figure 2(B)).

3.3. Fluorescence Microscopic Assay of Apoptosis in K562 Cells. In order to further determine the apoptosis effect of $\mathrm{VB}-\mathrm{Ni}$, next, we treated K562 cells with VB-Ni. Using AO/EB staining for apoptotic cells, apoptotic nuclei were identified by their characteristic features such as chromosomal condensation, distinctively marginated, and fragmented under fluorescence 

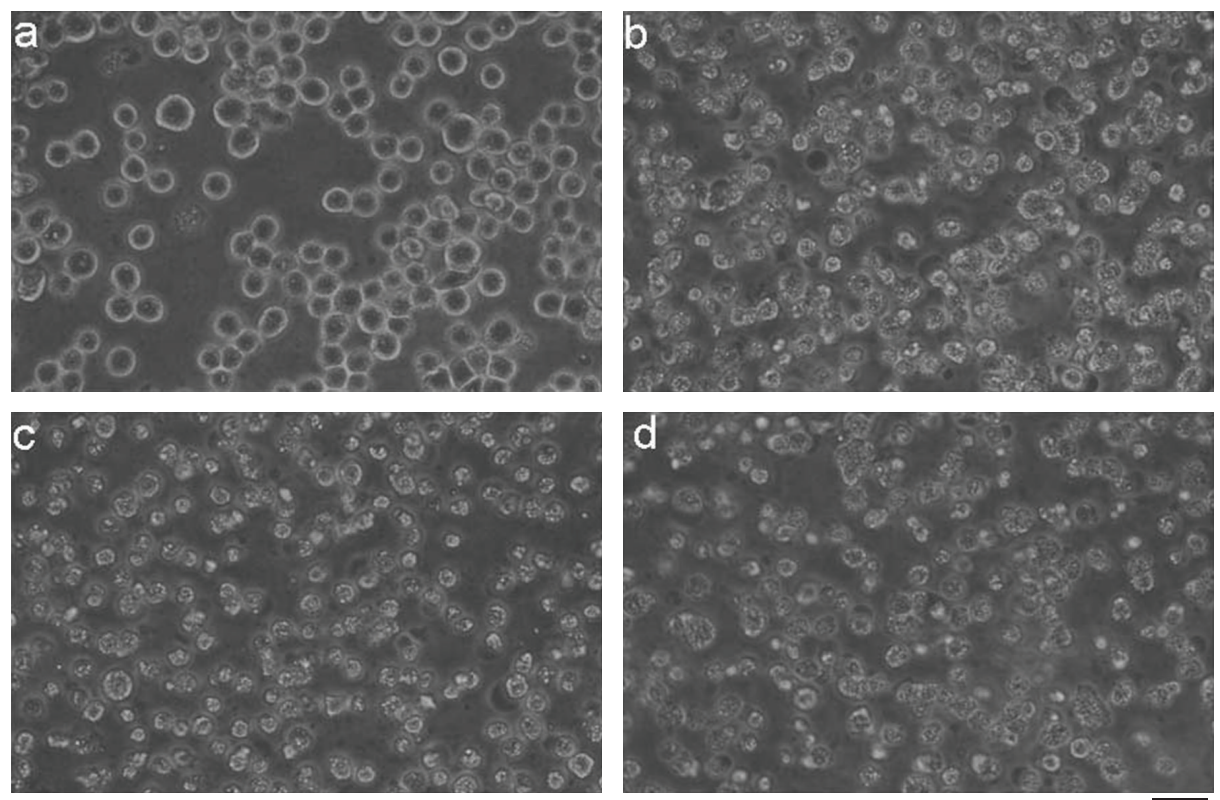

(A)

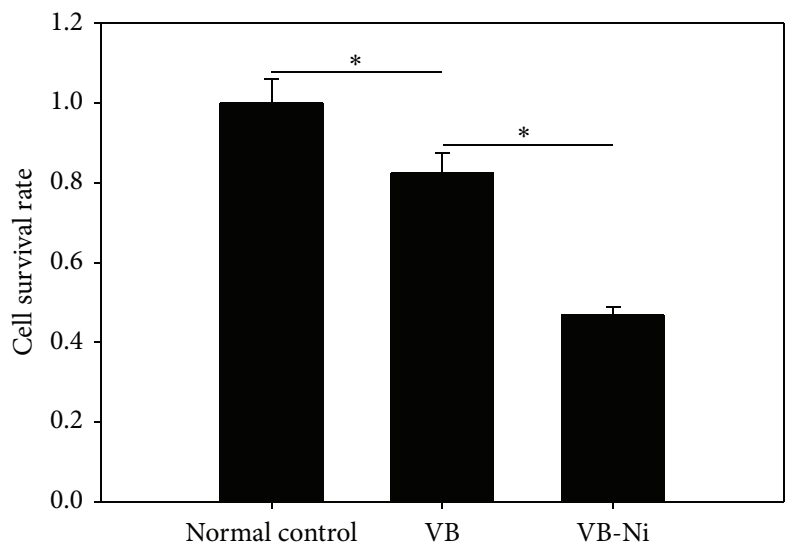

(B)

Figure 2: The effects of VB-Ni in recipient K562 cells. (A) K562 cells were treated with or without VB-Ni, VB for 48 h or 72 h, and then observed under microscopy. (a) Microscopy image of normal K562 cells. (b) K562 cells were treated with VB for 48 h. (c) K562 cells were treated with VB-Ni for $48 \mathrm{~h}$. (d) K562 cells were treated with VB-Ni for $72 \mathrm{~h}$. (scale bar $=100 \mathrm{~nm}$ ). (B) MTT measurement of cellular survival in $\mathrm{K} 562$ cells treated with VB or VB-Ni.

microscope. We found that the apoptotic nuclei in K562 cells treatment with VB-Ni (Figures 3(c) and 3(d)) were emerged compared with normal control (Figures 3(a) and 3(b)).

3.4. DNA Fragmentation Experiments. To figure out whether the cell growth inhibition was caused by the apoptotic response, the DNA fragmentations were examined by agarose gel electrophoresis. When K562 cells were treated with VB-Ni or VB (Figure 4), the intensity of fragmented chromosomal DNA bands was much higher than that observed from cells untreated (Figure 4, lanes 1 and 2, resp.) in a fixed time interval (i.e., $24 \mathrm{~h}$ (a), $48 \mathrm{~h}$ (b), and $72 \mathrm{~h}$ (c)). The formation of DNA ladders was clearly present after treatment with VB-Ni (Figure 4, lane 1) but was only weakly discernible when the cells were treated with VB (Figure 4, lane 2). Our observations support the hypothesis that the remarkable enhancement of apoptosis was induced by the synergistic effect of VB-Ni nanoparticles on K562 cells.

3.5. VB-Ni Inhibits the Tumor Growth In Vivo. We next tested whether delivery of VB-Ni can efficiently suppress the implanted tumor growth in mice. In this experiment, C57 mice were subcutaneously implanted with K562 tumor cells. Mice were intravenously injected with different reagents every other day. After 20 days, the treatment with VB-Ni effectively reduced the volume (Figures 5(a) and 5(b)) or weight (Figure 5(c)) of the implanted tumors compared with VB-treated control. These data strongly suggest that the VB$\mathrm{Ni}$ can transfer Ni into the mouse implanted tumor cells, in 


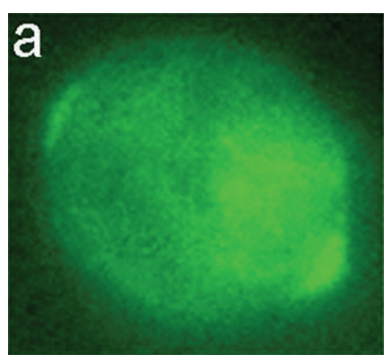

(a)

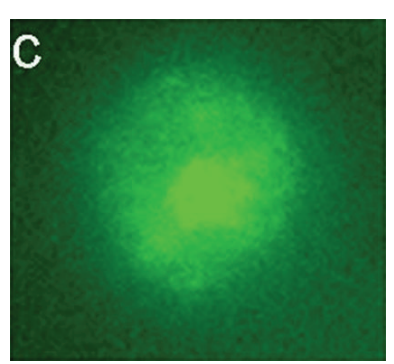

(c)

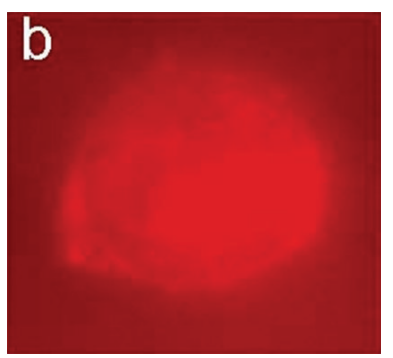

(b)

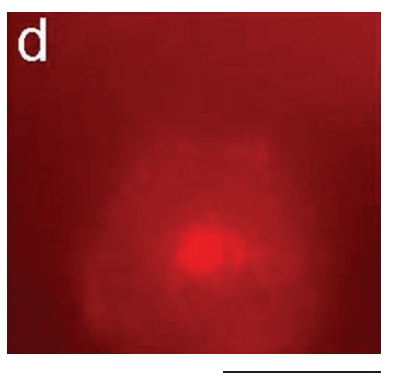

(d)
FIgURE 3: Fluorescence detection of the apoptosis of K562 cell. Detect the normal and apoptotic K562 cells by Acridine orange/ethidium bromide (AO/EB) staining. (a) Early apoptotic nuclei of normal control K562 cells were observed. (b) Later apoptotic nuclei of normal control K562 cells were observed. (c) Early apoptotic nuclei of treatment K562 cells with VB-Ni were observed. (d) Later apoptotic nuclei of treatment K562 cells with VBNi were observed (400x). (bar $=10 \mu \mathrm{m})$.

which Ni with VB suppresses the tumor cell growth (plus a magnet fixed under skin close to the tumor site).

\section{Discussion}

In this study, we demonstrated that a combination of verbascoside (VB) and Ni where the VB is bound to Ni surface by electrostatic interaction will suppress the growth of tumor cells. Compared with VB-Ni, the same or even higher concentration of $\mathrm{VB}$ did not cause a significant reduction in cell viability in K562 cells. However, when K562 cells were treated with VB-Ni, we observed a remarkable enhancement of cell growth inhibition (Figure 2). The results strongly suggest that the VB-Ni nanoparticles can induce cell growth inhibition of K562 cell in vitro.

Two major types of cell death are recognized: apoptosis and necrosis [27]. Apoptosis is a regulated process that can be triggered by different stimuli and is mediated by a cascade of enzymes. Necrosis is a catastrophic form of cell death which does not involve the regulated action of enzymes. Studies have demonstrated that the presence of smaller DNA fragments is believed to reflect the release of nucleosomes from apoptotic cells and higher molecular weight DNA molecules are believed to reflect release from necrotic cells. Apoptosis results in fragmentation of cells into apoptotic bodies which are engulfed by neighboring cells and macrophages. However, uptake of necrotic cells

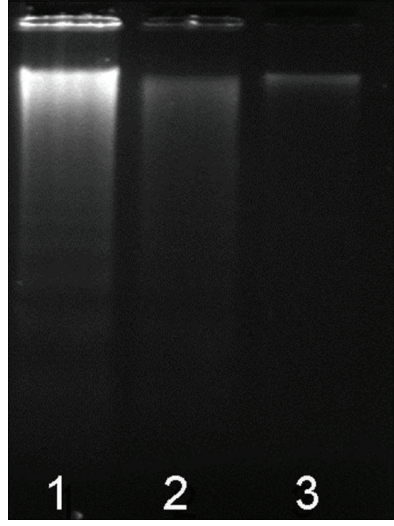

(a)

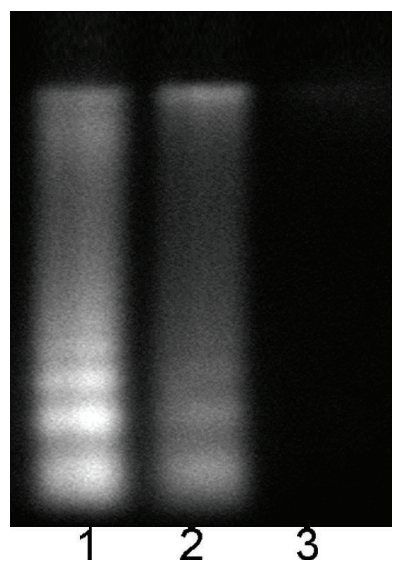

(c)

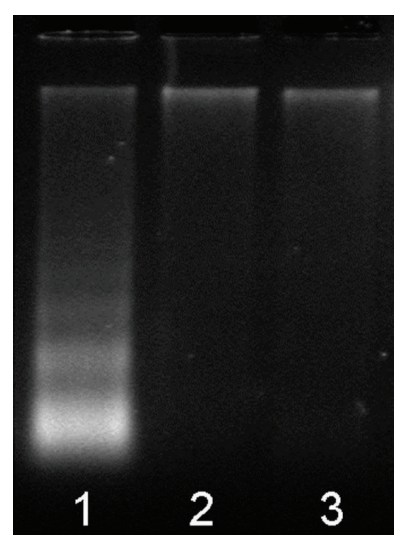

(b)

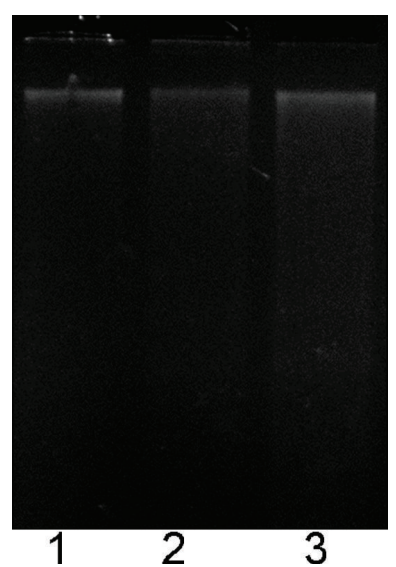

(d)
FIGURE 4: DNA fragmentation in K562 cells after different treatments. Genomic DNA was extracted from K562 cells treated with various regents using Apoptotic DNA ladder isolation kit and then loaded onto $1 \%$ agarose gel. Then, DNA ladders were visualized under UV light with ethidium bromide staining. (a) K562 cells were treated with VB-Ni (lane 1), VB (lane 2), or control (lane 3) treatment for $24 \mathrm{~h}$. (b) K562 cells were treated with VB-Ni (lane 1), VB (lane 2), or control (lane 3) treatment for $48 \mathrm{~h}$. (c) K562 cells were treated with VB-Ni (lane 1), VB (lane 2), or control (lane 3) treatment for $72 \mathrm{~h}$. (d) Normal K562 cells.

has been reported to be less efficient than phagocytosis of apoptotic cells. So active anticancer drugs which induce apoptosis in malignant cells should be a main way to clinical antitumor. Interestingly, we found that VB-Ni can induce K562 cell apoptosis with a rate significantly higher than that of $\mathrm{VB}$, or $\mathrm{Ni}$ alone treatment in vitro. Moreover, we analyzed the cells apoptosis morphology from various assays, nuclei staining. When cells were treated with VB-Ni, they exhibited characteristic morphological features of apoptosis, such as chromosomal condensation and DNA fragment.

As the above results illustrated, we recognized the evidence of apoptosis of cancer cells in vitro. It is possible that VB-Ni could play a critical role in inducing apoptosis in vivo. The tumor growth in group 3 mice (treated with $\mathrm{VB}-\mathrm{Ni}$ ) (Figure 5(b)) was suppressed most efficiently. 


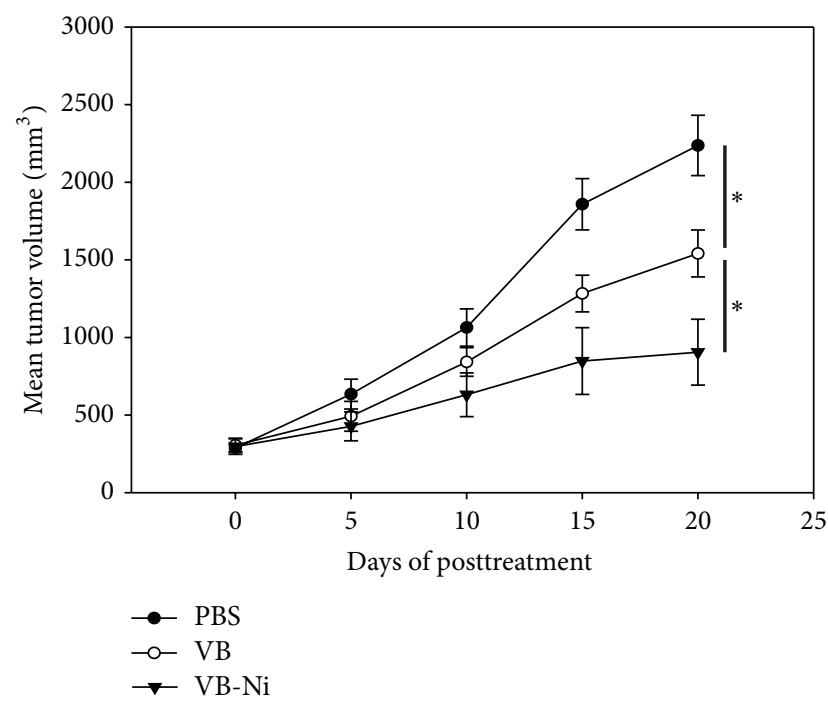

(a)

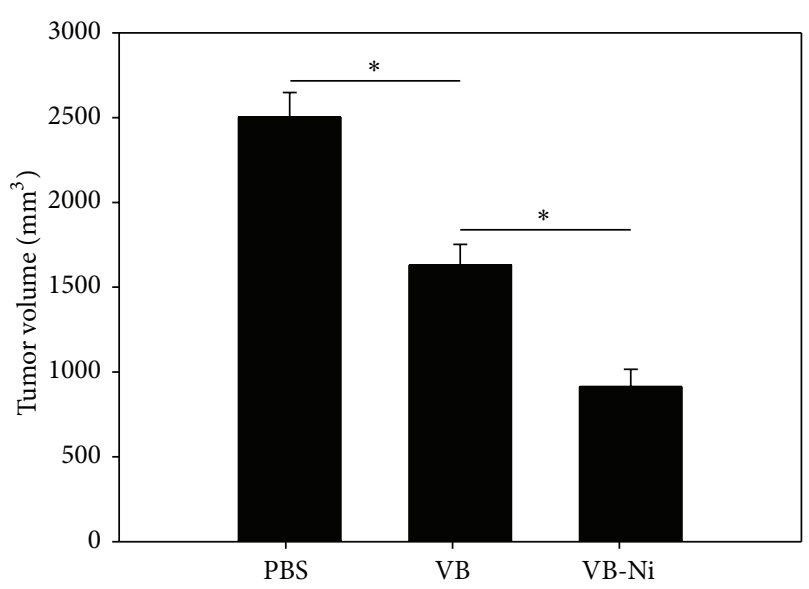

(b)

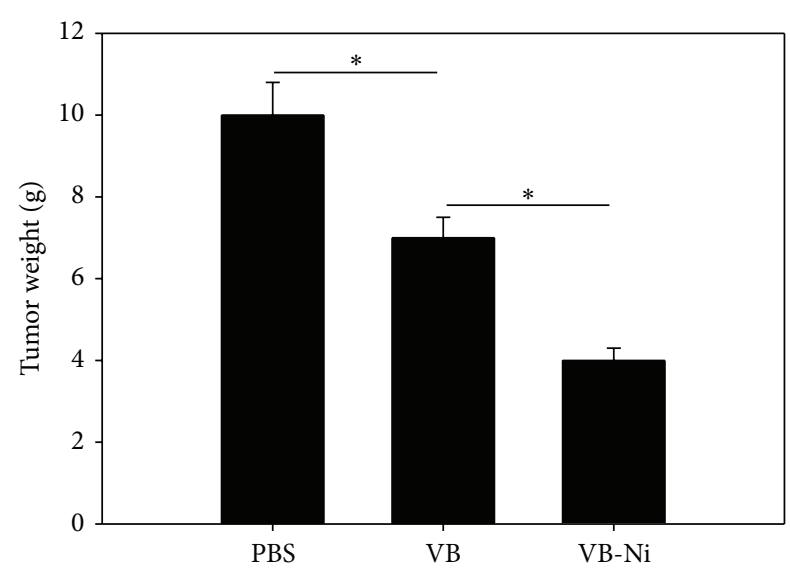

(c)

FIGURE 5: Inhibit the tumor growth in K652/ADM mice with VBNi treatments. (a) and (b) Tumor volumes in mice treated with various regents. Cancer cells were injected into the abdominal area of mice (plus a magnet fixed under skin close to the tumor site). When the tumors reached a minimal size of $300 \mathrm{~mm}^{3}$, mice were divided to 3 groups with 3-5 mice in each group. The mouse groups received various reagents every other day by tail-vein injections. (c) The weight of tumor in (a).

\section{Conclusion}

In summary, in the current study, we have investigated the synergistic effect of $\mathrm{Ni}$ with the anticancer drug verbascoside (VB) on the induction of apoptosis of K562 cell. Our observations demonstrate that $\mathrm{Ni}$ readily facilitated the uptake of the VB into K562 cells by electrochemical assay. Apoptotic staining and DNA fragmentation further demonstrate that treatment of VB-Ni can clearly activate apoptosis in K562 cells. Moreover, our in vivo study indicates that the treatment of VB-Ni effectively inhibited the mice tumor growth. The increased cell apoptosis rate was closely correlated with the enhanced inhibition of tumor growth in the studied animals (plus a magnet fixed under skin close to the tumor site). Thus, VB-Ni may serve as a novel strategy to sensitively track the respective cancer cells for efficient cancer chemotherapy.

\section{Authors' Contribution}

Mingyue Chen, Yaqin Zhang, and Bin Huang contributed equally to this work.

\section{Acknowledgments}

This research was financially supported by the Priority Academic Program for the Development of Jiangsu Higher Education Institutions (JX10531801/005), Medical Science and Technology Foundation of Jiangsu, Department of Health (Z201008), NSFC (31201003), Funding from the State Key Laboratory of Bioelectronics of Southeast University, Nanjing Medical University Science and Technology Development Fund (KY1011431121612218 and KY1011431121612230), and Science and Technology Innovation Supporting Fund (JX10131801147, JX10131801149, and JX10131801154).

\section{References}

[1] G. Zhang, X. Zeng, H. L. Yue, P. Li, and X. H. Zhao, "Evaluation of the antitumor activity by cdte qds with verbascoside," Nano, vol. 08, no. 03, Article ID 1350031, 2013.

[2] S. Yu, G. Wu, X. Gu et al., "Magnetic and pH-sensitive nanoparticles for antitumor drug delivery," Colloids and Surfaces B, vol. 103, pp. 15-22, 2013.

[3] M. Bououdina, S. Rashdan, J. L. Bobet, and Y. Ichiyanagi, "Nanomaterials for biomedical applications: synthesis, characterization, and applications," Journal of Nanomaterials, vol. 2013, Article ID 962384, 4 pages, 2013.

[4] S. Li, Z. Niu, X. Zhong et al., "Fabrication of magnetic $\mathrm{Ni}$ nanoparticles functionalized water-soluble graphene sheets nanocomposites as sorbent for aromatic compounds removal," Journal of Hazardous Materials, vol. 229-230, pp. 42-47, 2012.

[5] S. Larumbe, C. Gomez-Polo, J. I. Perez-Landazabal et al., "Ni doped $\mathrm{Fe}_{3} \mathrm{O}_{4}$ magnetic nanoparticles," Journal of Nanoscience and Nanotechnology, vol. 12, no. 3, pp. 2652-2660, 2012.

[6] G. Zhang, X. Zeng, and P. Li, "Nanomaterials in cancer-therapy drug delivery system," Journal of Biomedical Nanotechnology, vol. 9, no. 5, pp. 741-750, 2013.

[7] D. Guo, C. Wu, X. Li, H. Jiang, X. Wang, and B. Chen, "In vitro cellular uptake and cytotoxic effect of functionalized nickel 
nanoparticles on leukemia cancer cells," Journal of Nanoscience and Nanotechnology, vol. 8, no. 5, pp. 2301-2307, 2008.

[8] J. Li, C. Wu, Y. Dai et al., "Doxorubicin-CdS nanoparticles: a potential anticancer agent for enhancing the drug uptake of cancer cells," Journal of Nanoscience and Nanotechnology, vol. 7, no. 2, pp. 435-439, 2007.

[9] I. Brigger, C. Dubernet, and P. Couvreur, "Nanoparticles in cancer therapy and diagnosis," Advanced Drug Delivery Reviews, vol. 54, no. 5, pp. 631-651, 2002.

[10] Z. Q. Yu, R. M. Schmaltz, T. C. Bozeman et al., "Selective tumor cell targeting by the disaccharide moiety of bleomycin," Journal of the American Chemical Society, vol. 135, no. 8, pp. 2883-2886, 2013.

[11] Y. Cui, Q. Wei, H. Park, and C. M. Lieber, "Nanowire nanosensors for highly sensitive and selective detection of biological and chemical species," Science, vol. 293, no. 5533, pp. 1289-1292, 2001.

[12] S. A. Schonbichler, L. K. Bittner, J. D. Pallua et al., "Simultaneous quantification of verbenalin and verbascoside in Verbena officinalis by ATR-IR and NIR spectroscopy," Journal of Pharmaceutical and Biomedical Analysis, vol. 84, pp. 97-102, 2013.

[13] L. Speranza, S. Franceschelli, M. Pesce et al., "Antiinflammatory effects in THP-1 cells treated with verbascoside," Phytotherapy Research, vol. 24, no. 9, pp. 1398-1404, 2010.

[14] L. Funes, O. Laporta, M. Cerdán-Calero, and V. Micol, "Effects of verbascoside, a phenylpropanoid glycoside from lemon verbena, on phospholipid model membranes," Chemistry and Physics of Lipids, vol. 163, no. 2, pp. 190-199, 2010.

[15] A. Santoro, G. Bianco, P. Picerno et al., "Verminoside- and verbascoside-induced genotoxicity on human lymphocytes: involvement of PARP-1 and p53 proteins," Toxicology Letters, vol. 178, no. 2, pp. 71-76, 2008.

[16] C. Zhao, G. Dodin, C. Yuan et al., "In vitro' protection of DNA from Fenton reaction by plant polyphenol verbascoside," Biochimica et Biophysica Acta, vol. 1723, no. 1-3, pp. 114-123, 2005.

[17] Y. Shi, W. Wang, Y. Shi et al., "Fast repair of dAMP hydroxyl radical adduct by verbascoside via electron transfer," Science in China C, vol. 42, no. 6, pp. 626-627, 1999.

[18] C. Zhang, N. Awasthi, M. A. Schwarz, S. Hinz, and R. E. Schwarz, "Superior antitumor activity of nanoparticle albuminbound paclitaxel in experimental gastric cancer," PLoS ONE, vol. 8, no. 2, Article ID e58037, 2013.

[19] S. Xin, X. Li, Y. Zhu et al., "Nanofibrous mats coated by homocharged biopolymer-layered silicate nanoparticles and their antitumor activity," Colloids and Surfaces B, vol. 105, pp. 137-143, 2013.

[20] A. F. Ourique, S. Azoubel, C. V. Ferreira et al., "Lipid-core nanocapsules as a nanomedicine for parenteral administration of tretinoin: development and in vitro antitumor activity on human myeloid leukaemia cells," Journal of biomedical nanotechnology, vol. 6, no. 3, pp. 214-223, 2010.

[21] M. H. El-Dakdouki, E. Pure, and X. Huang, "Development of drug loaded nanoparticles for tumor targeting. Part 2: enhancement of tumor penetration through receptor mediated transcytosis in 3D tumor models," Nanoscale, vol. 5, no. 9, pp. 3904-3911, 2013.

[22] B. Auffinger, R. Morshed, A. Tobias, Y. Cheng, A. U. Ahmed, and M. S. Lesniak, "Drug-loaded nanoparticle systems and adult stem cells: a potential marriage for the treatment of malignant glioma?” Oncotarget, vol. 4, no. 3, pp. 378-396, 2013.
[23] B. Behl, I. Papageorgiou, C. Brown et al., "Biological effects of cobalt-chromium nanoparticles and ions on dural fibroblasts and dural epithelial cells," Biomaterials, vol. 34, no. 14, pp. 35473558, 2013.

[24] D. Fourches, D. Pu, and A. Tropsha, "Exploring quantitative nanostructure-activity relationships (QNAR) modeling as a tool for predicting biological effects of manufactured nanoparticles," Combinatorial Chemistry and High Throughput Screening, vol. 14, no. 3, pp. 217-225, 2011.

[25] C. Andary, R. Wylde, C. Laffite, G. Privat, and F. Winternitz, "Structures of verbascoside and orobanchoside, caffeic acid sugar esters from Orobanche rapum-genistae," Phytochemistry, vol. 21, no. 5, pp. 1123-1127, 1982.

[26] L. Ji, Z. Yun, Z. Hong, S. Baoning, and Z. Rongliang, "Differentiation of human gastric adenocarcinoma cell line MGc80-3 induced by verbascoside," Planta Medica, vol. 63, no. 6, pp. 499502, 1997.

[27] T. A. Taton, C. A. Mirkin, and R. L. Letsinger, "Scanometric DNA array detection with nanoparticle probes," Science, vol. 289, no. 5485, pp. 1757-1760, 2000. 

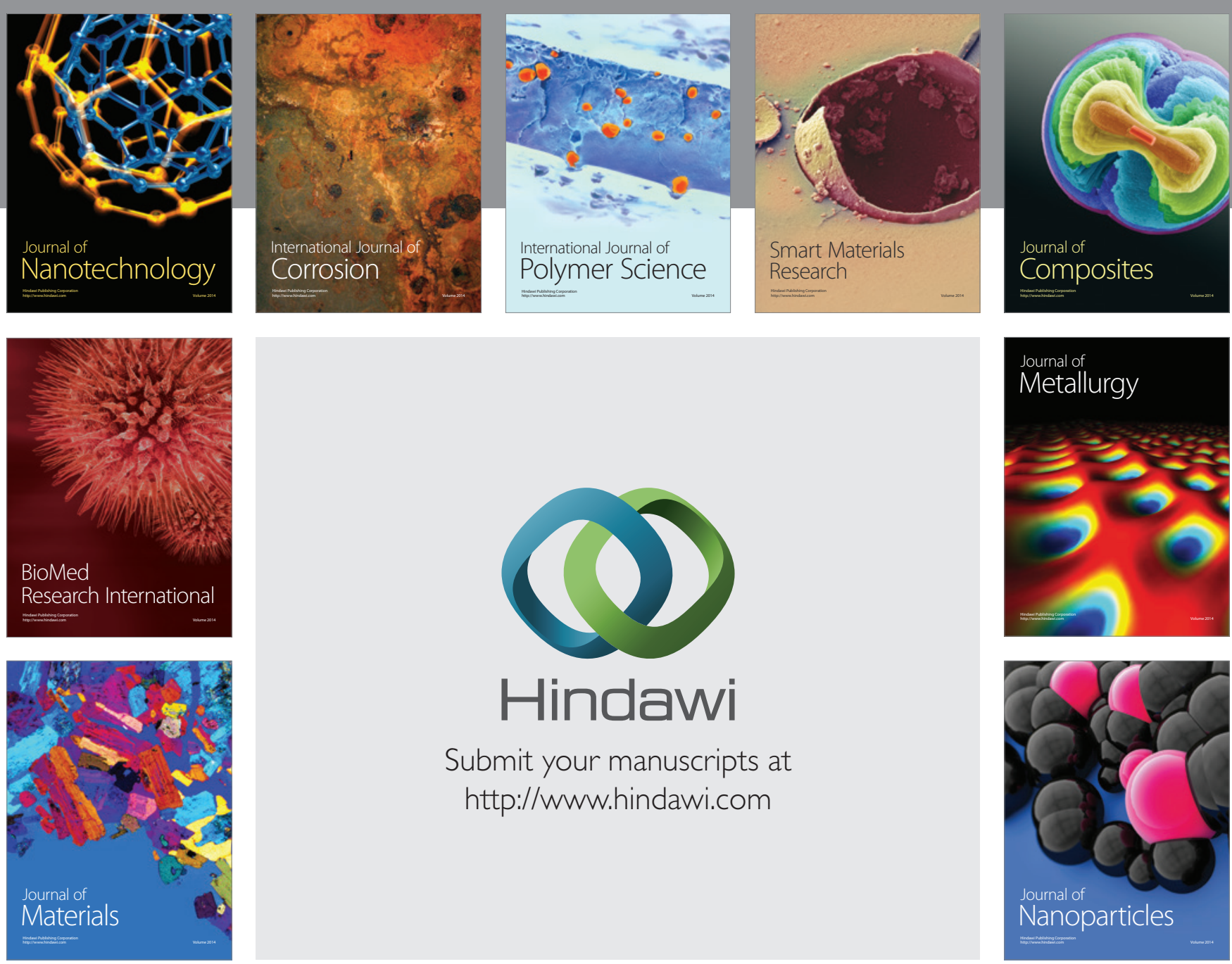

Submit your manuscripts at http://www.hindawi.com
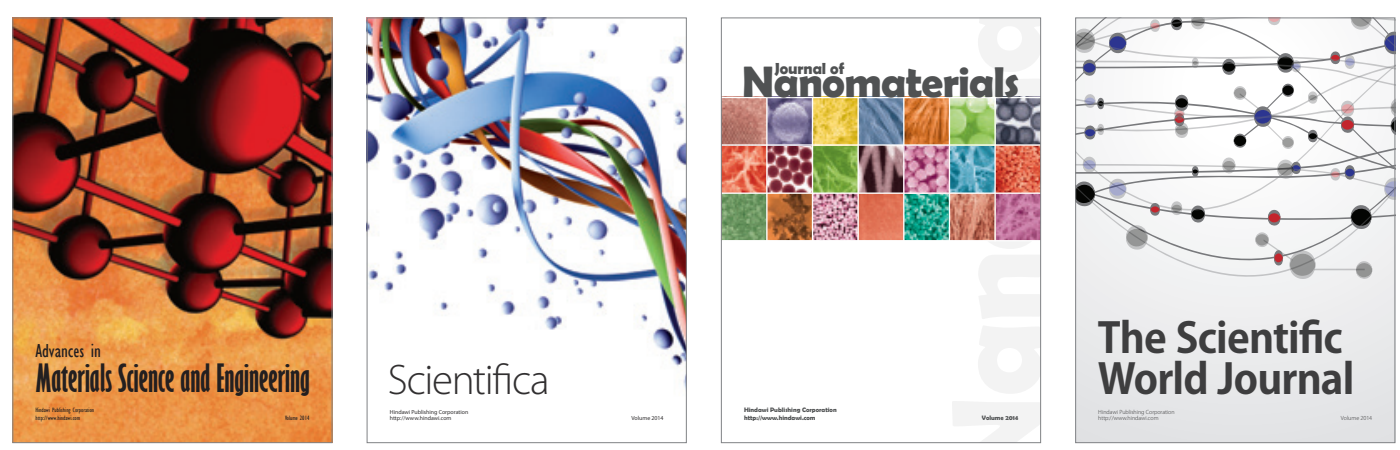

\section{The Scientific World Journal}
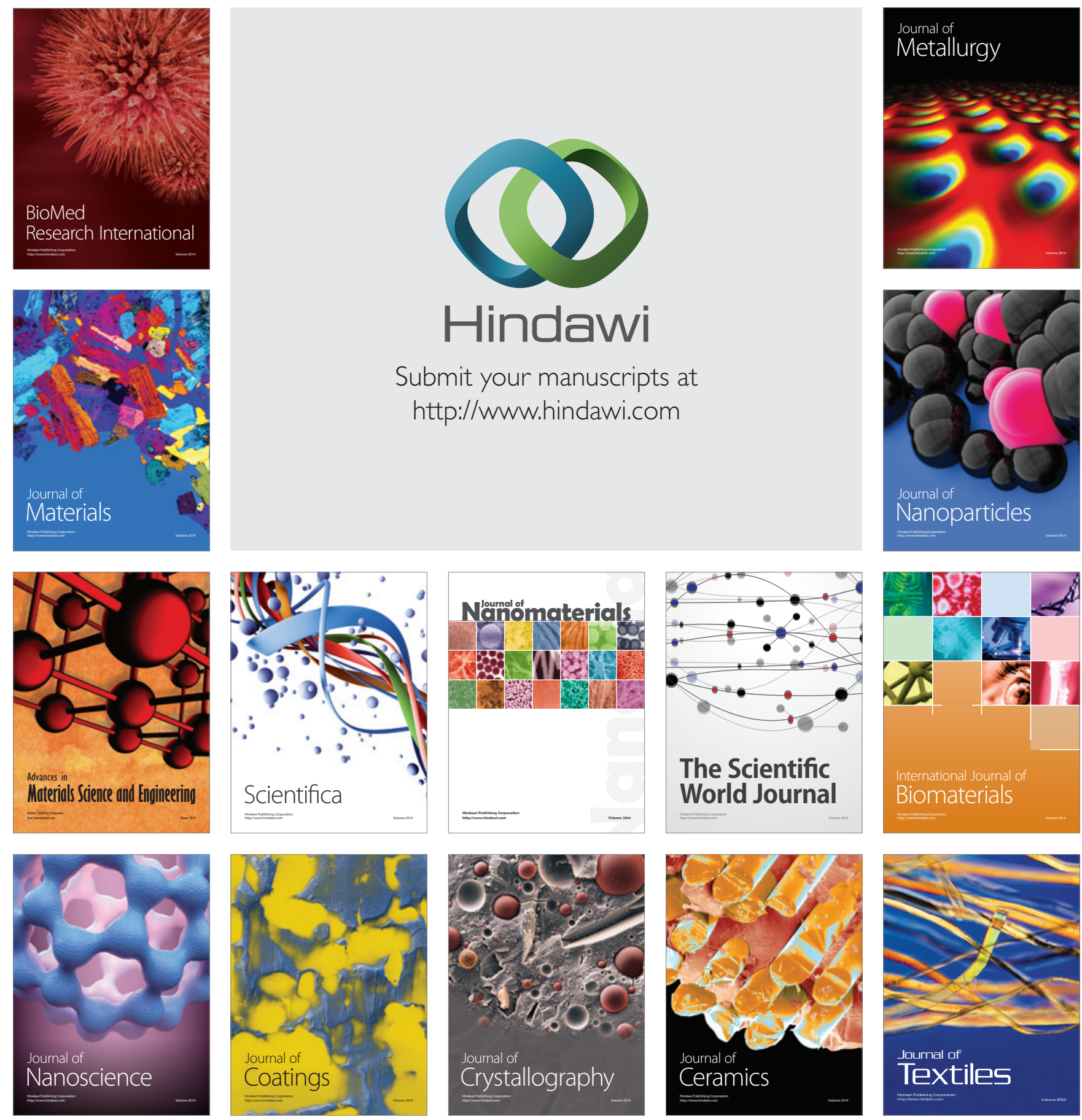